\section{Marking of Patent Medicines}

When the question of withdrawing Medicine Stamp Duties was debated recently in the House of Commons, it was clear that there was a general fecling that proprietary medicines should not be freed from all restrictions, but should be subjected to effective control. Some of them are fraudulent, their advertisements encourage healthy people to think they are ill, and unhealthy people to postpone taking medical advice until it is too late, and some of them are poisons. The recent passing of effective legislation in the United States was largely due to the fact that seventy-three people were killed by an elixir containing diethylene glycol, just at the time when the matter was being debated in Congress. It would be unfortunate if another such accident were to occur in Great Britain before effective measures were introduced. Reforms of various kinds are being widely discussed. Prof. A. J. Clark, in a little tract published last year under the title "Patent Medicines" said : "The clearest line for the Government to take would be to say that it did not wish to tax any remedy that was beneficial to the health of tho people, and wished to suppress all those that wero useless and harmful." This would imply regulations such as those now enacted in the United States, where new remedies can only bo sold when they have been officially approved. Lord Horder, in his speech in the House of Lords, stressed the harm that is done by misleading advertisements and recommended that measures for the control of quack medicines should form part of the campaign for national fitness.

\section{Organization for War Emergency}

Exrensive preparations are in progress to meet a possible war emergency, not only in regard to defence, but also in other directions. On the medical side, the Ministry of Health has issued a "Statement Relating to the Emergency Hospital Organisation, First Aid Posts and Ambulances" (London : H.M. Stationery Office. 4d. net). This sets out, in the first place, emergency hospital requirements and organization, schemes for dealing with casualties and ambulance services. A summary is then given of supplies that are being provided. These include 200,000 beds with mattresses, 320,000 blankets, with a corresponding sufficiency of sheets, pillows, pillowslips and towels, and 226,000 stretchers with 400,000 coloured blankets. In addition, drugs and dressings to the value of $£ 237,000$ are on order, as well as surgical equipment and appliances sufficient for 75,000 casualty beds. On the food side, the Government has advised all who can to lay in a week's store of emergency food. In order to translate the Government's advico into practical terms, the British Medical Association has issued a booklet, which should be in the hands of every householder ("How to Stock your A.R.P. Larder". 2d.). This gives advice on the stores that should be purchased in order to provide a week's food supply for a family of five. The approximate cost of the articles suggested is given, together with hints for storage and use, a few sample recipes for one dinner, and the food values of the rations mentioned.

\section{Nutrition and the Public Health}

THE proceedings of one of the most useful conferences of recent years-the National Conference on the Wider Aspects of Nutrition organized by the British Medical Association and held in London at the end of April-have recently been published under the title "Nutrition and the Public Health" (B.MI.A. House, V.C.1. Pp. 150. 2s. 6d. post paid). This conference, a report of which appeared in NATUnE of May 6, p. 745, brought together representatives of medicine, agriculture, industry, administration and education to discuss in a comprehensivo way the relation of human nutrition to the national welfare. It urged upon the Government the formulation of a long-term food policy in which the requirements of health, agriculture and industry should be considered in mutual relation, and recommended the inauguration of an educational campaign to make such a policy effective. The Conference ranged over a wide field, but as the published proceedings clearly indicate, there was the thread of the urgent need for an active, informed Government policy, which should take as its main objective the abolition of malnutrition, running through every discussion. The common benefit to the health of the individual citizen, to the prosperity of the home farmer (who would be largely responsible for the perishable 'protective' foods so essential to such a scheme) and to the efficiency of industry of such a policy forms the triple basis of what is undoubtedly one of the clearest and most influential appeals yet made for the early application of modern nutritional knowledgo to national wellbeing.

\section{Teachers on Modern Education}

THE addresses delivered at sectional meetings arranged in connexion with the recent annual conference at Llandudno of the National Union of Teachers (Hamilton House, Mabledon Place, London, W.C.1) have been issued as a bound pamphlet. 'They' include one by Mr. Kenneth M. Lindsay on the development of our educational system, in which he suggests that a commission is required on the whole financial relation between central and local government if the implications of the Spens Report are to be carried out. He also stresses the need for doveloping technical education, including the provision of improved premises and closer co-operation between technical education and industry and commerce. Emphasizing the importance of adult education, he pointed out the need for an effective survey of this field. ' r. C. F. Strong's address on the teaching of citizenship in central schools refers to the importance of including the civic aspects of science in a science syllabus, and urges the importance of history as laying the foundation for the teaching of citizenship and dispassionate thinking about political questions. Mr. E. R. J. Hussey's paper on aspects of education considered as a preparation for life in the modern world also emphasizes the importance of science, especially biology, from this point of view as well as the importance of character training and the formulation of ideals and a sense of values. Dr. G. $H$. 